\title{
Spindle cell oncocytoma of the pituitary gland with follicle-like component: organotypic differentiation to support its origin from folliculo-stellate cells
}

\author{
Istvan Vajtai · Jürgen Beck • Andreas Kappeler • \\ Ekkehard Hewer
}

Received: 13 April 2011/Revised: 1 May 2011/Accepted: 5 May 2011/Published online: 18 May 2011

(C) Springer-Verlag 2011

\begin{abstract}
Spindle cell oncocytoma (SCO) is a rare, nonadenomatous tumor originating from the anterior pituitary gland. Composed of fusiform, mitochondrion-rich cells sharing several immunophenotypic and ultrastructural properties with folliculo-stellate cells (FSC), SCO has been proposed to represent a neoplastic counterpart of the latter. To date, however, SCO has failed to meet one criterion commonly used in histological-based taxonomy and diagnostics; that of recapitulating any of FSCs' morphologically defined developmental or physiological states. We describe a unique example of SCO wherein a conventional fascicular texture was seen coexisting with and organically merging into follicle-like arrangements. The sellar tumor of $2.7 \times 2.6 \times 2.5 \mathrm{~cm}$ was transphenoidally resected from a 55 -year old female. Preoperative magnetic resonance imaging indicated an isointense, contrast enhancing mass with suprasellar extension. Histology showed multiple rudimentary to well-formed, follicle-like cavities on a classical spindle cell background; while all the participating cells exhibited an SCO immunophenotype, including positivity for S100 protein, vimentin, EMA, Bcl-2, and TTF-1, as well as staining with the antimitochondrial antibody
\end{abstract}

I. Vajtai $(\bowtie) \cdot$ E. Hewer

Neuropathology Service, Institute of Pathology,

University of Bern, Murtenstrasse 31,

PO Box 62, 3010 Bern, Switzerland

e-mail: istvanvajtai@yahoo.com

J. Beck

Department of Neurosurgery, University Hospital ("Inselspital")

Bern, Bern, Switzerland

A. Kappeler

Laboratory of Diagnostic Immunohistochemistry,

University of Bern, Bern, Switzerland
113-1. Conversely no expression of GFAP, follicular-epithelial cytokeratin, carcinoembryonic antigen, or anterior pituitary hormones was detected. Ultrastructurally, tumor cells facing follicular lumina displayed organelles of epithelial specialization, in particular surface microvilli and apical tight junctions. This constellation is felt to be reminiscent of FSCs' metaplastic transition to follicular epithelium, as observed during embryonic development and physiological renewal of the hormone-secreting parenchyma. Such finding is apt to being read as a supporting argument for SCO's descent from the FSC lineage.

Keywords Spindle cell oncocytoma . Folliculo-stellate cells · Organoid differentiation . Follicle-like metaplasia $\cdot$ Pituitary cytogenesis

\section{Introduction}

Spindle cell oncocytoma (SCO) is an uncommon adenohypophysial tumor composed of mitochondrion-rich, fusiform cells, with a characteristic immunophenotype and no demonstrable hormonal activity $[9,22]$. In the context of its exclusive predilection for the anterior pituitary, the immunoprofile and ultrastructure of SCO have been construed to indicate its being a neoplasm of folliculo-stellate cells (FSCs).

In fact, SCO cells bear little microscopic resemblance to native FSCs; nor does the fairly monotonous morphology of the hitherto known examples of SCO seem to reflect any of FSCs' functional-related phenotypic variations [1, 12]. Indeed, reported nonstandard examples of SCO tend to document features of aggressive behavior rather than any significant departure from its conventional histology $[6-8,16]$. 
Involvement with the embryogenesis and the life cycle of follicular-epithelial cells probably represents the most readily observable facet of FSCs' functions [2, 12]. Specifically, a subset of FSCs have been shown to directly contribute to the renewal of endocrine parenchyma by undergoing epithelial transformation. To date, only one recent report by Horvath et al. [13] revealed ultrastructural evidence of "quasi-follicular" organelles in two SCO-like tumors; these invite reading as the "missing link" in the argument for SCOs' actually sharing some of FSCs' dynamic properties.

In the following, we describe an hitherto not documented phenomenon of overtly follicle-like differentiation within an otherwise classical SCO. This pattern is felt to recapitulate FSCs' potential to participate in follicular cytogenesis.

\section{Case report}

\section{Clinical history}

The 55-year old woman was discovered to harbor a sellar space-occupying lesion while being medically prepared for hip joint replacement surgery. Her past medical history had included type 2 diabetes mellitus, dyslipidemia, and arterial hypertension, as well as the patient's reporting "estrogen therapy in childhood for short stature". Neurological examination, including perimetric visual field assessment, was unremarkable. Endocrinologic laboratory testing, on the other hand, indicated panhypopituitarism without evidence of diabetes insipidus or secondary hyperprolactinemia. Cranial magnetic resonance imaging (MRI) revealed a voluminous yet noninvasive intra- and suprasellar tumor of $2.7 \times 2.6 \times$ $2.5 \mathrm{~cm}$ (Fig. 1). On a presumptive diagnosis of nonfunctioning pituitary adenoma, the lesion was totally resected via transnasal-transphenoidal approach. The patient made an uneventful recovery, and has been discharged on hormonal substitution therapy.
Materials and methods

The surgical specimen comprised 11 tissue fragments of $0.1-0.6 \mathrm{~cm}$ diameter each, totalling $1.8 \times 0.8 \times 0.3 \mathrm{~cm}$. After overnight fixation in $10 \%$ buffered formalin, the tissue block was routinely processed to paraffin, and $3 \mu \mathrm{m}$ thick serial sections stained with hematoxylin and eosin (H.E.), Gomori's silver (Ag) impregnation for reticulin, and periodic acid-Schiff's reagent (PAS). Immunohistochemistry was performed with the following panel of antibodies: S100 protein (polyclonal; Dako, Glostrup, Denmark), Bcl-2 (clone 124; Dako), epithelial membrane antigen-EMA (clone E29; Dako), carcinoembryonic antigen-CEA (clone II-7; Dako), thyroid transcription factor 1-TTF-1 (clone SPT24; Leica Biosystems, Newcastle-upon-Tyne, UK), vimentin (clone Vim 3B4; Dako), mitochondrial antigen (clone 113-1; BioGenex, San Ramon, CA, USA), cytokeratin 8 (clone CAM5.2; BD Biosciences, San Jose, CA, USA), synaptophysin (clone 27G12; Leica Biosystems), chromogranin A (polyclonal; Dako); NCAM (clone 123C3; Sanbio, Uden, The Netherlands), GFAP (clone 6F2; Dako, Glostrup, Denmark), smooth muscle actin (clone 1A4; Sigma, St. Louis, MO, USA), CD34 (clone QBend/10; Dako), Ki-67 (clone MIB1; Dako), as well as PRL, GH, ACTH, TSH, LH, FSH, and $\alpha$-subunit. The specifications for the anterior pituitary hormones and details of the immunohistochemical protocol used have been documented previously [26]. Slides were developed with polymer-bound horseradish peroxidase (Envision+; Dako) and 3,3'-diaminobenzidine as chromogen.

For ultrastructural study, representative tissue fragments were retrieved from the paraffin block, postfixed in glutaraldehyde and transferred to Spurr's Resin (SERVAHeidelberg, Germany) for ultrathin sectioning. Grids were contrasted with uranyl acetate and lead citrate, and viewed in a Zeiss E10 transmission electron microscope.
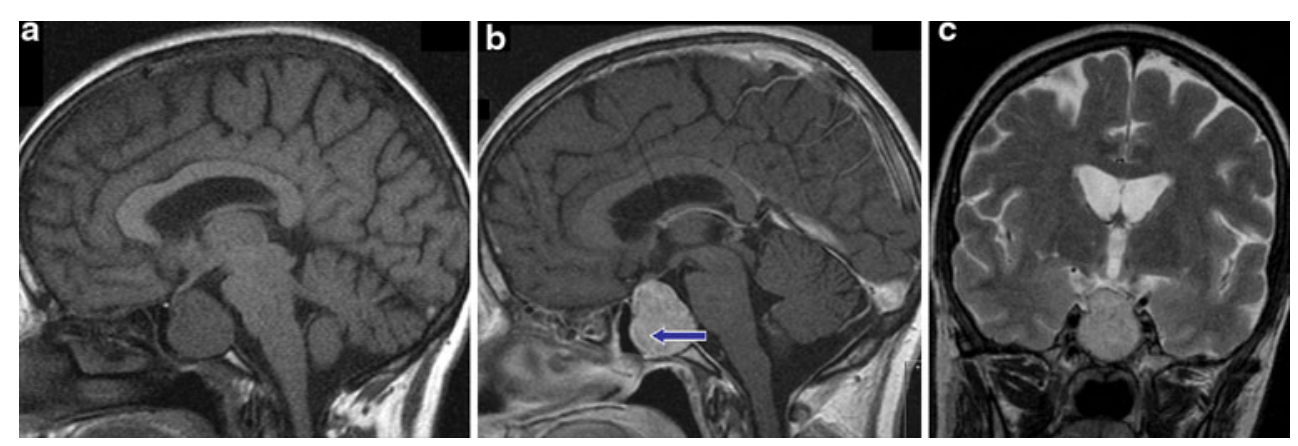

Fig. 1 Preoperative imaging findings. Sagittal $\mathrm{T}_{1}$-weighted (a) and post-Gadolinium (b) sequences to show well circumscribed, isointense, homogeneously enhancing mass with ballooning of the sella and suprasellar extension. Semilunar cleavage plan (arrow) suggests minimal residual anterior pituitary parenchyma. Frontal $\mathrm{T}_{2}$-weighted sequence (c) indicates lack of involvement of carotid sinuses 
Pathological findings

Light microscopy revealed a moderately cellular solid neoplasm, wherein fusiform to plump roundish cells tended to segregate along a biphasic architectural pattern (Fig. 2a). The prevailing component consisted of compact fascicles with sweeping or rudimentarily intersecting profiles, the individual cells variously exhibiting chromophobic to granular-eosinophilic, and PAS-negative cytoplasm (Fig. 2b). The second moiety involved a scatter of folliclelike lumina encircled by radially arranged tumor cells (Fig. 2c). These cavities tended to be devoid of any secretion (Fig. 2d); nor did their lining cells rest on a basement membrane (Fig. 2e). In addition to such discrete foci, there were several transitional areas of follicle-like differentiation, including dehiscences of tumor cells along slit-like channels or small nests centered around a punctate vacuole (Fig. 2f). Largely devoid of atypia, the majority of tumor cell nuclei had round to ovoid contours. Mitotic activity was absent, as were microvascular proliferation and necrosis. Alongside the tumor, the material also contained a sizable fragment of adenohypophysial parenchyma-which was taken advantage of as an internal control to assess the quality of the immunostains described below. Residues of neurohypophysis were not identified.

Regardless of architectural variations, the tumor cells showed coexpression of S100 protein, vimentin, Bcl-2, and TTF-1, along with granular staining for the antimitochondrial antibody 113-1 (Fig. 2g-k). Staining for EMA tended to produce a rather faint cytoplasmic signal; conspicuously, however, the apical surface of tumor cells along the follicle-like lumina was intensely decorated (Fig. 21). Conversely, no juxtanuclear "dots" were detected. Throughout the tumor, immunoreactions for CAM5.2, CEA, GFAP, CD56/NCAM, CD34, $\alpha$-SMA, chromogranin $\mathrm{A}$, as well as those for anterior pituitary hormones yielded negative results. Interestingly, a small minority of tumor cells amidst the conventional fusiform population featured Golgi-pattern positivity for synaptophysin (Fig. 2m). There were an average of 1.5-2\% MIB1-immunoreactive nuclei. Despite poor preservation of ultrastructure, organelles indicative of epithelial specialization were readily identified in lumen-forming tumor cells by electron microscopy (Fig. 2n-p). On account of these findings, a diagnosis of SCO (WHO grade I) was issued along with a comment regarding the nonstandard aspects of its histology.

\section{Discussion}

We observed a novel, previously not documented pattern of follicle-like differentiation in SCO. Although such constellation may seem to contradict the definition of SCO as a non-epithelial tumor, both the basic texture and the immunophenotype of the present lesion do comply with those of "classical" SCO [6-9, 11, 16, 22]. These include mitochondrion-rich elongated cells, which coexpress S100 protein, vimentin, and EMA; while being largely devoid of either follicular-epithelial or glial qualities, as reflected by their reluctance to staining with cytokeratins or GFAP. Lack of neurosecretory phenotype, including pituitary hormones, has been regarded implicit to diagnosis, as well. Moreover, with the recent demonstration of nuclear TTF-1 expression by $\mathrm{SCO}$, its histogenesis has been put into a developmentally meaningful context [17].

While none of the above markers is specific, their coexpression on an appropriate histological background will distinguish SCO from its look-alikes.

Conversely, the unexpected follicle-like motive seen in our case is apt to ruling in a few differential diagnostic alternatives that call for systematic exclusion.

Secretory meningioma regularly includes a spindle cell component, and may indeed exhibit triple coexpression of EMA, vimentin, and S100 protein [4]. In addition, however, its periluminal cells are conspicuously positive for cytokeratins and CEA-a finding not present in the follicle-like structures observed by us. Moreover, the latter appeared "empty" rather than containing eosinophilic colloid as seen in secretory meningioma. It is of anecdotal interest to note that the first case description of a pituitary tumor of purported FSC origin (see below) was precisely challenged by the alternative of secretory meningioma [28, 31].

Schwannian tumors may also occasionally bring forth pseudoglandular clefts as well as true heterologous glandular differentiation-although the latter phenomenon almost exclusively arises in high-grade lesions (i.e., MPNST) [21, 30]. While the rare actual examples of sellar region Schwannoma on record are all of conventional type [18], at least one published report on benign glandular Schwannoma affecting a cranial nerve lends some plausiblity to such differential diagnosis [5].

Salivary gland-type tumors of the pituitary are particularly apt to generating a differential diagnostic dilemma [10]. Indeed, their versatile morphology often encompasses both spindle cell and oncocytic patterns; and expression of S100 protein, EMA, and GFAP may be part of their immunoprofile, as well. Nevertheless, whether on a spindle cell or oncocytic background, the adenomatous element of salivary gland tumors invariably involves cytokeratin expressing dimorphic epithelia wherein basal cells exhibit a myoepithelial phenotype.

The rare sellar ependymomas represent yet another differential diagnostically appealing variation on the biphasic architectural theme [24]. Indeed, the radial arrays of tumor cells along round to slit-like lumina in our case 


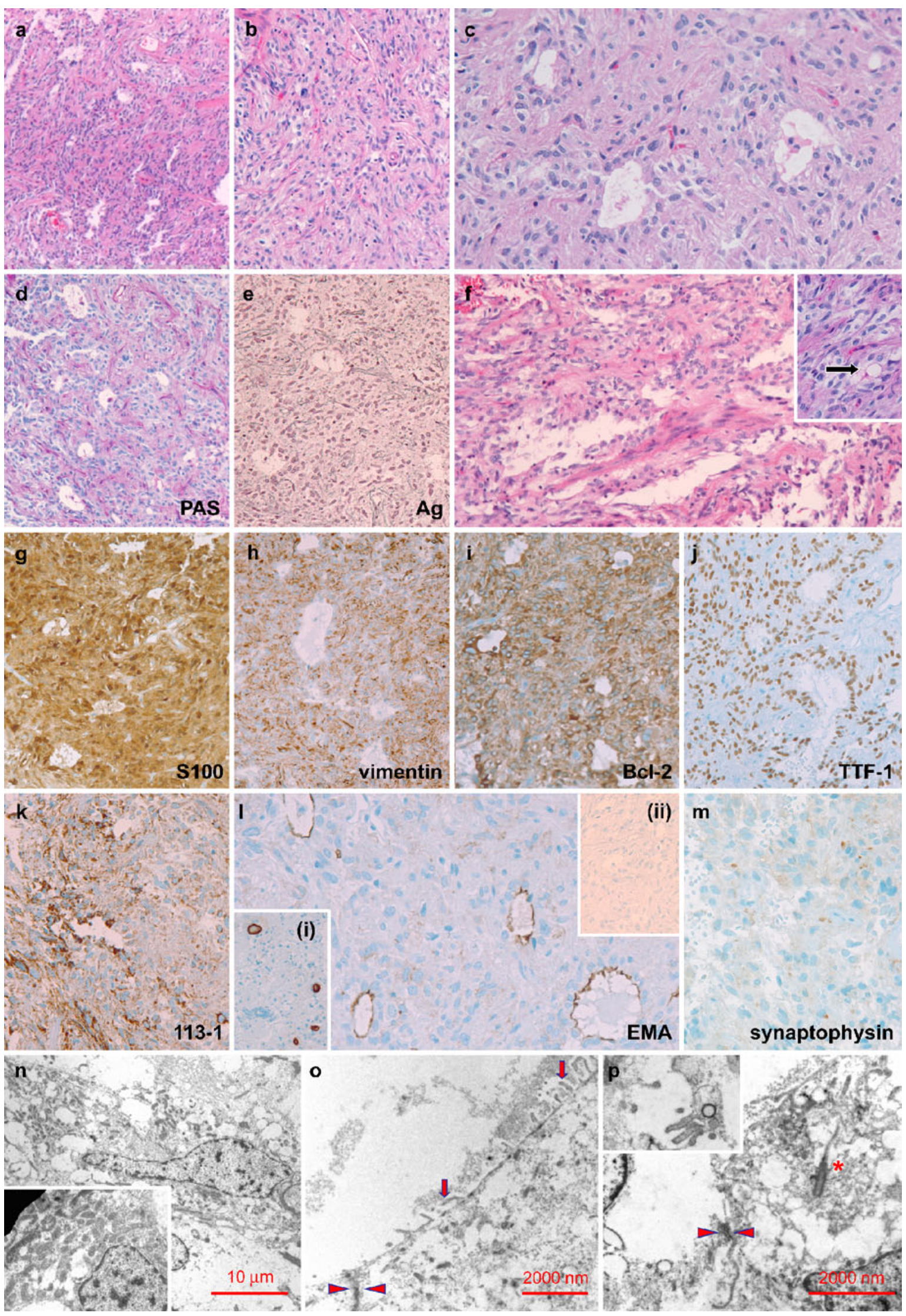


4 Fig. 2 Histology, immunophenotype, and ultrastructure of follicleforming SCO. Low power view of a representative fragment to show solid architecture punctuated by follicle-like cavities. Overall eosinophilic hue of specimen (a). The lesion's conventional component consists of fascicles of spindle cells (b). Well-formed follicle-like structures involve cuboidal cells which tend to merge into their regular SCO neighborhood (c). Lumina are either optically lucent or only contain transudate-like PAS negative fluid (d). Follicle-lining cells consistently lack a circumferential basement membrane (e). Dehiscence-like spaces (f) and microlumina (inset: arrow) may represent intermediate stages of follicle-like differentiation. Irrespective of architectural variations, tumor cells consistently express traditional immunomarkers of SCO $(\mathbf{g}$ through $\mathbf{j})$. Mitochondrial immunostaining labels spindle cells and the follicles' lining alike (k). Polarity of cells facing lumina is revealed by EMA staining along their apical surface (1). Inset (i) reveals similarity to staining pattern of adenohypophysial follicles in nontumorous anterior pituitary gland. Lack of immunoreactivity for low molecular weight cytokeratin (ii) helps exclude residual pituitary gland parenchyma that would have been merely overrun by tumor. Golgi-pattern signal for synaptophysin in a small minority of tumor cells suggests an emerging neuroendocrine phenotype $(\mathbf{m})$. Ultrastructurally, spindle cells are replete with mitochondria in the conventional SCO component (n). A significant part of mitochondria are autolytic; their actual density is readily apparent in some better preserved areas (inset). Cells engaged in follicle formation (o) display epithelial surface microvilli (arrows) and junctions by terminal bars (arrowheads). Microlumina (p) contain amorphous material, plump microvilli (inset), as well as an occasional cilium (asterisk). Signet ring-like indentation of nucleus (lower right corner) and desmosomal contact between cells (arrowheads). Microphotographs $\mathbf{a}-\mathbf{c}$ and $\mathbf{f}$ represent H.E. stained slides. Original magnifications: a $60 \times$; b $100 \times$; c $400 \times$; d-m $200 \times$; scales for $\mathbf{n}-$ $\mathbf{p}$ are indicated by bars

readily call to mind ependymal tubules or contorted pseudoventricular cavities. Awareness of the recently described occurrence of oncocytic change in ependymoma may further induce to such interpretation [27]. Besides lacking GFAP immunoreactivity, the follicle-forming SCO described here did not show either the distinctive dot-like EMA staining of ependymoma, or its ultrastructural correlate [4]. While the thought-provoking hypothesis of sellar ependymoma being a variant of pituicytoma-therefore potentially related to $\mathrm{SCO}$ as well $[3,25]$ - has been put forward by Scheithauer et al., results of immunohistochemistry for TTF-1 have not been provided by these authors.

A numerically variable side population of FSCs-the presumed ancestors of SCO-have been known to regularly complement pituitary adenomas, as well [14, 29]. Of note, the designation "folliculo-stellate tumor" is being used by some authors as an interpretative shortcut to refer to $\operatorname{SCO}[7,11]$.

Historically, the earliest mention of FSCs as the prevailing neoplastic element has been made by Yagishita et al. [31]. Epithelial rather than fusiform in texture, the tumor described therein also included conspicuous mucous-filled acini.
In a series by Iwaki et al. [14] one hormonally inactive tumor out of 40 pituitary adenomas tested for the immunoexpression of S100 protein and GFAP was felt to be composed mostly by tumor cells of FSC origin. As depicted in Fig. 3 of that paper, these exhibited overtly epithelial qualities, as well as prominent follicle formation. Intriguingly, periluminal cells were explicitely described as being "rich in mitochondria" (Fig. 4 therein). Lack of reported data on EMA and cytokeratin staining, unfortunately, does not allow for further potential analogies with our case to be explored.

Of late, Min et al. [19] reported on a pediatric example of morphologically complex silent corticotroph cell adenoma, wherein a conventional endocrine-type epithelium was punctuated by mucinous glands. The latter, in turn, were felt to be intimately commingling with and reciprocally merging into what the authors interpreted as FSCs. It is suggested that these be regarded as neoplastic in nature, ones illustrating a process of "retrodifferentiation" of Rathke's pouch epithelium into hormone-secreting cells via FSCs. In fact, follicular differentiation involving an amphicrine phenotype is by no means exceptional in pituitary adenomas, the best known examples being pro-

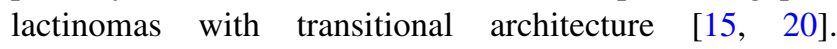
Nevertheless, the issue of FSCs' actual impact on the morphogenesis of such nearly physiological, organoid structures probably cannot be addressed adequately by direct inference from histology.

In our case, the very imperfection of the follicle-forming attempt is felt to represent a considerable advantage. While the tumor cells along the lumina displayed obvious hallmarks of epithelial commitment, in particular baso-apical polarization (as evidenced by surface asymmetry of EMA staining), they were still recognizable as $\mathrm{SCO}$ by virtue of both their conventional $\mathrm{S} 100^{+} /$vimentin ${ }^{+} / \mathrm{Bcl}-2^{+} / \mathrm{TTF}-1^{+} /$ CAM5.2 $2^{-}$immunoprofile, as well as ultrastructurally. A novel finding, Golgi-pattern positivity for synaptophysin in a small minority of tumor cells additionally invites reading as an indice of emerging phenotypical switch to adenohypophysial epithelium.

A recent account on electron microscopic evidence of hybrid FSC/follicular-epithelial organelles in two SCO-like pituitary tumors by Horvath et al. probably represents what comes closest to our findings [13]. Indeed, the villous microlumina observed therein quite exactly anticipate the elementary ultrastructural traits of the follicle-like component in the present report. Of particular interest is the demonstration of neurosecretory granules in case 2 of Horvath et al.-which is apt to indirectly corroborating the relevance of focal synaptophysin immunostaining seen by us. We strongly agree with the authors' claim that such morphological peculiarities be regarded as a replica of FSCs' plasticity as an epithelial precursor during both 
adenohypophysial development and follicular renewal in the adult pituitary. For the sake of completeness, mention be made of a unique example of "pituitary blastoma" recently reported by Scheithauer et al. [23]. Possibly maldevelopmental in origin, with its architecture reminiscent of the pituitary gland at gestational age 10-12 weeks, FSCs were not felt to significantly participate in the proliferative compartment of this tumor.

In conclusion, it is tempting to regard the above example of follicle-like differentiation as one additional piece of morphologic evidence linking SCO to the FSC lineage.

Acknowledgments We wish to thank Ms. Mirjam Janzi for the histotechnical handling of the material. The immunohistochemical reactions referred to in this report have been executed by Mrs. Micaela Güdel, Christine Steffen, and Ellen Lanz. Processing for electron microscopy was done by Mrs. Isabelle Estella. Referencing has been assisted by Mrs. Sibylle Graf and Irène Marconi-Geiser.

\section{References}

1. Allaerts W, Vankelecom H (2005) History and perspectives of pituitary folliculo-stellate cell research. Eur J Endocrinol 153:1-12

2. Asa SL, Kovacs K, Laszlo FA, Domokos I, Ezrin C (1988) Human fetal adenohypophysis: electron microscopic and ultrastructural immunocytochemical analysis. Neuroendocrinology 48:423-431

3. Brat DJ, Scheithauer BW, Staugaitis SM, Holtzman RNN, Morgello S, Burger PC (2000) Pituicytoma. A distinctive low-grade glioma of the neurohypophysis. Am J Surg Pathol 24:362-368

4. Burger PC, Scheithauer BW (2007) Tumors of the central nervous system. AFIP Atlas of Tumor Pathology, Series 4, Fascicle 7, Washington

5. Callagy G, Thornton J, Rawluk D, Farrell MA (2000) Benign glandular peripheral nerve sheath tumor of the seventh and eighth cranial nerve complex. Clin Neuropathol 19:104-107

6. Casar Borota O, Scheithauer BW, Fougner SL, Hald JK, RammPettersen J, Bollerslev J (2009) Spindle cell oncocytoma of the adenohypophysis: report of a case with marked cellular atypia and recurrence despite adjuvant treatment. Clin Neuropathol 28:91-95

7. Coiré CI, Horvath E, Smyth HS, Kovacs K (2009) Rapidly recurring folliculostellate cell tumor of the adenohypophysis with the morphology of a spindle cell oncocytoma: case report with electron microscopic studies. Clin Neuropathol 28:303-308

8. Demssie YN, Joseph J, Dawson T, Roberts G, de Carpentier J, Howell S (2009) Recurrent spindle cell oncocytoma of the pituitary, a case report and review of the literature. Pituitary doi: 10.1007/s11102-009-0170-6

9. Fuller GN, Scheithauer BW, Roncaroli F, Wesseling P (2007) Spindle cell oncocytoma. In: Louis DN, Ohgaki H, Wiestler OD, Cavenee WK (eds) WHO Classification of Tumours of the Central Nervous System. IARC Lyon, pp 245-246

10. Hampton TA, Scheithauer BW, Rojiani AM, Kovacs K, Horvath E, Vogt P (1997) Salivary gland-like tumors of the sellar region. Am J Surg Pathol 21:424-434

11. Hori S, Hayashi N, Fukuoka J, Kurimoto M, Hamada H, Miyajima K, Nagai S, Endo S (2009) Folliculostellate cell tumor in pituitary gland. Neuropathology 29:78-80
12. Horvath E, Kovacs K (2002) Folliculo-stellate cells of the human pituitary: a type of adult stem cell? Ultrastruct Pathol 26:219-228

13. Horvath E, Coire CI, Kovacs K, Smyth HS (2010) Folliculostellate cells of the human pituitary as adult stem cells: examples of their neoplastic potential. Ultrastruct Pathol 34:133-139

14. Iwaki T, Kondo A, Takeshita I, Nakagaki H, Kitamura K, Tateishi J (1986) Proliferating potential of folliculo-stellate cells in human pituitary adenomas. Immunohistochemical and electron microscopic analysis. Acta Neuropathol 71:233-242

15. Kepes JJ (1978) Transitional cell tumor of the pituitary gland developing from a Rathke's cleft cyst. Cancer 41:337-343

16. Kloub O, Perry A, Tu PH, Lipper M, Lopes MBS (2005) Spindle cell oncocytoma of the adenohypophysis. Report of two recurrent cases. Am J Surg Pathol 29:247-253

17. Lee EB, Tihan T, Scheithauer BW, Zhang PJ, Gonatas NK (2009) Thyroid transcription factor 1 expression in sellar tumors: a histogenetic marker? J Neuropathol Exp Neurol 68:482-488

18. Maartens NF, Ellegally DB, Vance ML, Lopes MBS, Laws ER Jr (2003) Intrasellar Schwannomas: report of two cases. Neurosurgery 52:1200-1206

19. Min HS, Lee SJ, Kim SK, Park SH (2007) Pituitary adenoma with rich folliculo-stellate cells and mucin-producing epithelia arising in a 2-year old girl. Pathol Int 57:600-605

20. Nishio S, Mizuno J, Barrow DL, Takei Y, Tindall GT (1987) Pituitary tumors composed of adenohypophysial adenoma and Rathke's cleft cyst elements: a clinicopathological study. Neurosurgery 21:371-377

21. Robinson CA, Curry B, Rewcastle NB (2005) Pseudoglandular elements in schwannomas. Arch Pathol Lab Med 129:1106-1112

22. Roncaroli F, Scheithauer BW, Cenacchi G, Horvath E, Kovacs K, Lloyd RV, Abell-Aleff P, Santi M, Yates AJ (2002) "Spindle cell oncocytoma" of the adenohypophysis. A tumor of folliculostellate cells? Am J Surg Pathol 26:1048-1055

23. Scheithauer BW, Kovacs K, Horvath E, Kim DS, Osamura RY, Ketterling RP, Lloyd RV, Kim OL (2008) Pituitary blastoma. Acta Neuropathol 116:657-666

24. Scheithauer BW, Swearingen B, Hedley Whyte T, Auluck PK, Stemmer-Rachamimov AO (2009) Ependymoma of the sella turcica: a variant of pituicytoma. Hum Pathol 40:435-440

25. Ulm AJ, Yachnis AT, Brat DJ, Rhoton AL (2004) Pituicytoma: report of two cases and clues regarding histogenesis. Neurosurgery $54: 753-758$

26. Vajtai I, Sahli R, Kappeler A, Christ ER, Seiler RW (2006) Leiomyomatoid angiomatous neuroendocrine tumor (LANT) of the pituitary: a distinctive biphasic neoplasm with primitive secretory phenotype and smooth muscle rich stroma. Acta Neuropathol 111:278-283

27. Vajtai I, von Gunten M, Fung C, Brekenfeld C, Kappeler A, Reinert MM (2011) Oncocytic ependymoma: A new morphological variant of high-grade ependymal neoplasm composed of mitochondrion-rich epithelioid cells. Pathol Res Pract 207:49-54

28. Vogel H, Horoupian DS, Silverberg G (1988) Do folliculo-stellate adenomas of the pituitary gland exist or are they intrasellar meningiomas? Acta Neuropathol 77:219-223

29. Voit D, Saeger W, Ludecke DK (1999) Folliculo-stellate cells in pituitary adenomas of patients with acromegaly. Pathol Res Pract 195:143-147

30. Woodruff JM, Christensen WN (1993) Glandular peripheral nerve sheath tumors. Cancer 72:3618-3628

31. Yagishita S, Itoh Y, Nakazima S, Suzuki N, Hirata K, Yamashita T (1984) Folliculo-stellate cell adenoma of the pituitary. A light and electron-microscopic study. Acta Neuropathol 62:340-344 